\title{
Design for Usability; practice-oriented research for user-centered product design
}

\author{
Daan van Eijk ${ }^{\mathrm{a}}$, Jasper van Kuijk ${ }^{\mathrm{a}}$, Frederik Hoolhorst ${ }^{\mathrm{b}}$, Chajoong Kim ${ }^{\mathrm{a}}$, Christelle Harkema ${ }^{\mathrm{c}}$, Steven Dorrestijn ${ }^{\mathrm{d}}$ \\ ${ }^{a}$ Faculty of Industrial Design Engineering, Delft University of Technology, Landbergstraat 15, 2628 CE, Delft, \\ The Netherlands \\ ${ }^{\mathrm{b}}$ Department of Engineering Technology, University of Twente \\ ${ }^{\mathrm{c}}$ Department of Industrial Design, Eindhoven University of Technology \\ ${ }^{\mathrm{d}}$ Department of Philosophy, University of Twente
}

\begin{abstract}
The Design for Usability project aims at improving the usability of electronic professional and consumer products by creating new methodology and methods for user-centred product development, which are feasible to apply in practice. The project was focused on 5 key areas: (i) design methodology, expanding the existing approach of scenario-based design to incorporate the interaction between product design, user characteristics, and user behaviour; (ii) company processes, barriers and enablers for usability in practice; (iii) user characteristics in relation to types of products and use-situations; (iv) usability decision-making; and (v) product impact on user behaviour. The project team developed methods and techniques in each of these areas to support the design of products with a high level of usability. This paper brings together and summarizes the findings.
\end{abstract}

Keywords: product usability; case study; user expectations; design practice; product development

\section{Introduction}

Whether a product is easy to use or not is referred to as its usability, a construct that originates from the field of human-computer interaction where it was applied to 'visual display terminals' [1]. Many perspectives on and definitions of usability have been developed over the years [2]. The definition of usability as formulated in the ISO 9241-11 Standard [3: p.2] contains what is considered the most accepted definition of usability $[4,5]$ : "the extent to which a product can be used by specified users to achieve specified goals with effectiveness, efficiency and satisfaction in a specified context of use."

It is argued that a high level of usability leads to increased productivity (quantity and quality of it), increased safety, and reduced effort for operation [69]. The absence of usability problems is considered to be closely linked to satisfaction about use $[10,11$, 12: p.2] and to how pleasurable people consider the product $[13,14]$. The level of usability of a product results in product returns, complaints or helpdesk calls [9, 15: p.66], negative word-of-mouth and changes in (re)purchase intent [16-18]. On the other hand, positive experiences with a product are said to result in a stronger brand position and (re)purchase intent $[16,18]$.

Recently signals have come from product development practice indicating that the usability of electronic consumer products is under pressure. In the past, product returns and complaints were largely due to technical failures (quality or reliability issues). Over time companies became better and better at managing product quality and until the late nineties the number of product returns decreased [15: p.3]. However, from that time on the number of product returns has been on the rise [19]. In a study by Den Ouden in $48 \%$ of products that were returned by consumers no technical fault could be detected [20: p.825]. This 'no-fault-found' category has been estimated to be $68 \%$ of returned electronic consumer products, and the cost for product returns for 2007 in the US market alone was put at $\$ 13.8$ billion [21]. Products being returned even though technically speaking they are not broken is partly attributed to 
people not understanding how to use a product properly and thinking that it does not work, as well as to consumers being dissatisfied with the product because it did not meet their expectations [20]. Improving the usability of products is seen as one of the strategies to deal with the rise in returns [21].

The Design for Usability (DfU) project aims at improving the usability of electronic professional and consumer products by creating new methodologies and methods for user-centred product development, which can be applied in practice.

\section{The 5 sub-projects}

The 5 research projects that completed the overall Design for Usability project are described individually in the following sections:

- Design Methodology

- Barriers and enablers for usability in practice

- User characteristics, Product type and Soft usability problems

- Improving usability decisions in design practice

- $\quad$ Product Impact

Each section introduces the background, aims, methodology and discussion related to each project.

\subsection{Design Methodology}

Previous research $[15,22,23]$ indicates that many of the complaints about usability find their origin in the organisation of the product development process. To deal with this issue, one of the aims of the Design for Usability project is to formulate a product development methodology that supports the development of usable products. Most companies already have a product development methodology (PDM) customized to their needs, to make the product development process (PDP) as effective and efficient as possible. To be able to apply the principles of the new proposed DfU methodology for usable products, while not forcing companies to overhaul their current product development processes, for each company and/or project a Plan of Approach (PoA) has to be specified which shows how the principles of the DfU methodology will be applied in the corporate PDMs [22, 24, 25].

Unfortunately in practice, product development teams often have an un-univocal, incomplete or wrong overview of a user-centred PoA. Practicebased research shows that, until now, PoAs for the user-centred aspects of product development processes are primarily defined based on the experience of the team members and are often not very specific which complicates the execution of the user-centred design activities [26, 27]. There are no tools to support product development teams in defining a univocal, effective and complete PoA for user-centred product development. The lack of a detailed and user-centred overview of the approach will, based on the product-process relation [28, 29], most certainly not lead to a product design that meets the intended use characteristics [26, 27].

This project has the aim of providing insights into how product development practitioners set up usercentred product development projects and how this could be improved. These insights are synthesized into a tool that supports product development teams in specifying a detailed user-centred PoA: the UCD Kick-Off Tool.

In four main steps the UCD Kick-Off Tool (see Fig. 1) guides product development teams to define a detailed PoA for user-centred product development, based on the specific characteristics of the product as well as the development environment. Since usability is only one of many aspects to consider in product development [27, 30, 31], this tool focuses on usability, but does not exclude other product aspects.

The UCD Kick-Off tool can be seen as a reference methodology discussing aspects that need to be considered while defining a usability and user-centred PoA. The tool is based on the assumption that an explicit and detailed definition of a user-centred PoA prevents usability problems. Input for the tool is a design brief describing desired basic product characteristics, process and project constraints and the core development team. The output of the tool is a detailed user-centred PoA describing intended product characteristics, intermediate development results, selected methods for (user-centred) product development, development activities, input per development activity and allocation of resources.

Step 1 - Stakeholder mapping: Conclusions by Hoolhorst [26] and Van Kuijk [27] demonstrate that a product developer's lack of a complete overview of stakeholders (both inside and outside the company) is an important aspect that causes of usability problems. Therefore the first step supports developers by making a complete overview and specification of stakeholders and prioritizing them. Where most stakeholder theories describe stakeholders in general terms, here stakeholder specification is tailored for use in user-centred PoA. 
Step 2 - Result planning: Cross states that detailed insight into the desired product characteristics as well as the intermediate results of the development process is needed in order to define a user-centred PoA [28]. Furthermore contextual conditions, such as available time and budget, influence the specification of the usability focused PDP [25, 27, 32]. However, most PDMs, such as Pahl \& Beitz [33] or VDI 2221 [34], seem to neglect these conditions. Therefore the second step focuses on making a detailed overview of product characteristics, scheduled intermediate development results and development process conditions.

Step 3 - Selection of (user-centred) development methods: Product developers are not aware of all the existing design methods and therefore do not use them. Furthermore Daalhuizen discusses that product developers automatically tend to stick to development methods they are familiar with without questioning if these development methods fit the intended development results [35]. Therefore the third step supports developers in exploring and selecting appropriate and feasible development methods, which will lead to the desired development results.

Step 4 - Development method specification: Selecting a method does not guarantee that its results will be available and can be implemented within the timeframe of a development project [27]. Further development method is needed [26, 27]. The fourth step therefore focuses on describing required development activities, required input per activity, development techniques and allocation of resources.

The UCD Kick-off tool is unique in its systematic support in defining a detailed user-centred development approach, as well as in its support for:

- Making a complete overview of stakeholders tailored for use in user-centred PoA;

- Defining and scheduling intermediate results based on both the content of the assignment as well as contextual conditions;

- Facilitating the exploration and selection of appropriate and feasible methods for usercentred product development;

- Specification of the actual application of the selected development methods.

\subsection{Barriers and enablers for usability in practice}

Even though there is a considerable body of knowledge about usability, with large numbers of available methods [36-38], the usability of electronic consumer products is under pressure [20, 21: p.825, $39,40]$. The cause for this pressure might lie in product development practice. However, as current literature on usability in practice does not take an integrated approach, contains few case studies, and only a limited number of studies investigate electronic

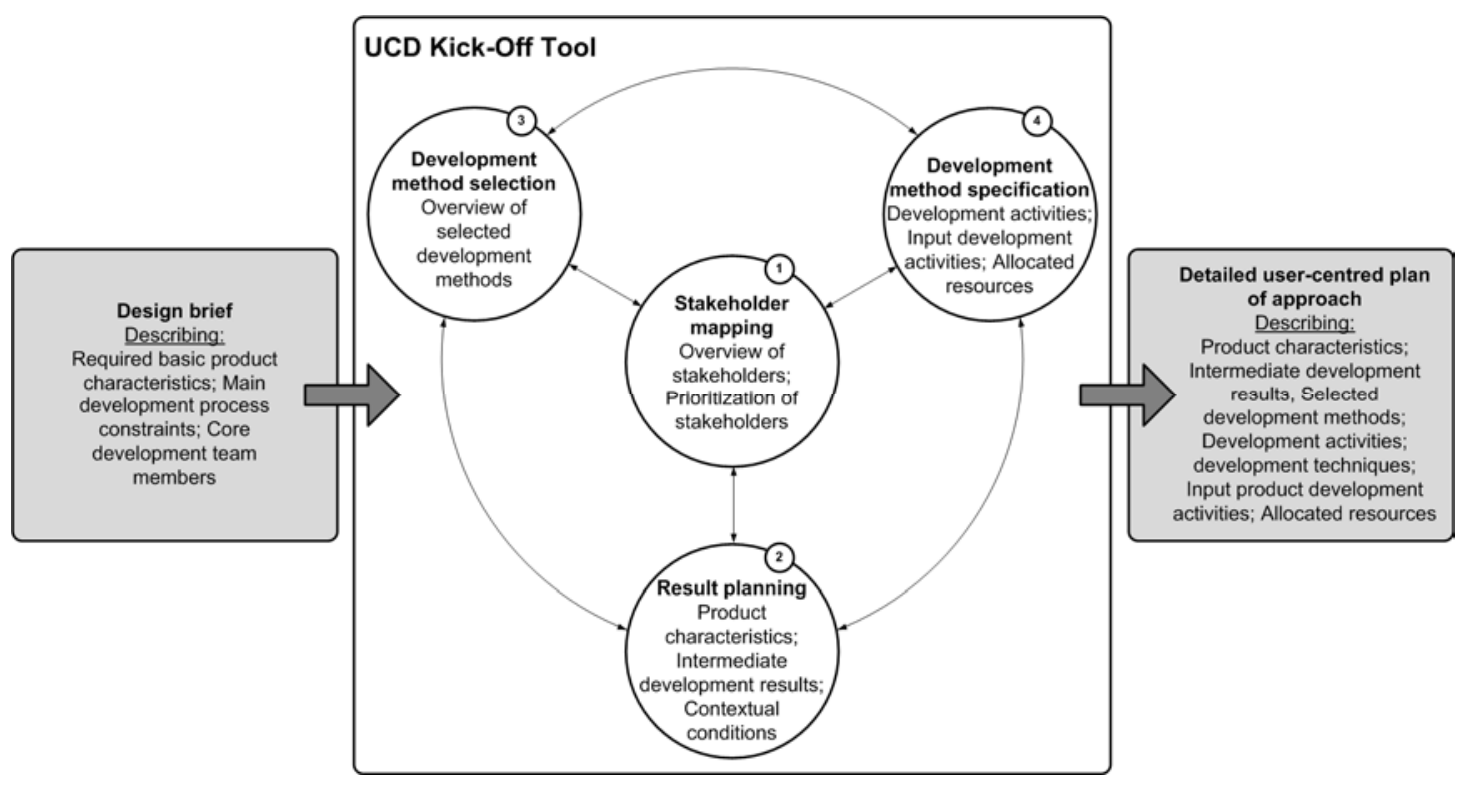

Figure 1: Overview of the UCD Kick-Off Tool describing four iterative steps 
sumer products specifically, there are few insights into how usability is dealt with in development of electronic consumer products.

The goal of this sub-project was to obtain insight into how usability is dealt with in the development of electronic consumer products as well as to identify factors in product development practice that contribute to or obstruct usability, and to investigate how these factors are related.

In total three case studies were conducted. The first was an interview-based case study, to explore how usability is dealt with in four sectors adjacent to the electronic consumer products market. Next an interview-based case study was conducted in the electronic consumer products sector at five major international product development groups. The goal of this study was to identify barriers and enablers for usability in practice. The third and final case study investigated the development history of three electronic consumer products within one product development group. This resulted in a detailed description of how the product development group dealt with usability and in two causal models. Based on the insights gained through the case studies as well as from existing research, 25 recommendations for industry were developed that describe how the author would organize a product development group if the goal is to make usable products.

In contrast to most existing research, which focuses mostly on usability specialists and their activities, in each of the case studies an integrated approach was taken, focusing on the whole product development process (as opposed to just evaluation or design) and including six roles that were considered to have the most influence on usability: the product manager, marketing specialist, industrial designer, interaction designer, usability specialist and development engineer.

Throughout each of the case studies, there was a dialogue with a company contact, and each study was concluded with a feedback workshop or workshops in which the results and conclusions were discussed with the informants. The recommendations for industry were 'user tested' by presenting them on the weblog of the researcher and by discussing them in a workshop with practitioners.
The results provide researchers with the possibility to conduct a comparison with case studies they conduct, and provide the insight they need to develop 'designer-centred' tools and methods. For practitioners the results can serve as a benchmark and help to identify problems in their own product development group. The recommendations for usability in practice provide actionable information on how to setup a user-centred product development organization.

\subsection{User characteristics, Product type, and Soft usability problems}

Usability refers to specific users, performing a specific task, with a specific product in a specific context [41, 42]. In addition, subjective satisfaction is a crucial dimension to define the concept of usability [43-45]. In analogy to soft reliability problems [46], soft usability problems are problems in which the most important issue is that users are unsatisfied about the quality of the interaction. Although the behaviour of users is one of the factors to play an important role in usability, the diversity in behaviour when interacting with products has only recently become serious object of study. In a globalizing market, a 'design for all' policy does not seem to work well, and local needs and demands appear to be increasingly important. These individual demands are not only shown between cultures or countries but also in subcultures or specific groups of people who share some characteristics or behaviour [47-49]. As a result, the development of products to satisfy diverse users has become more and more challenging thanks to the differing characteristics of the users.

To design products that satisfy their target users, a deeper understanding is needed of their user characteristics related to unexpected problems users face. These user characteristics encompass cognitive aspect, personality, demographics, and use behaviour (Figure 2). This study focuses on how user characteristics and product type can influence whether soft usability problems occur, and if so, which types. The study will lead to user profiles that provide an overview of the interaction between user characteristics, product type, and soft usability problems. 


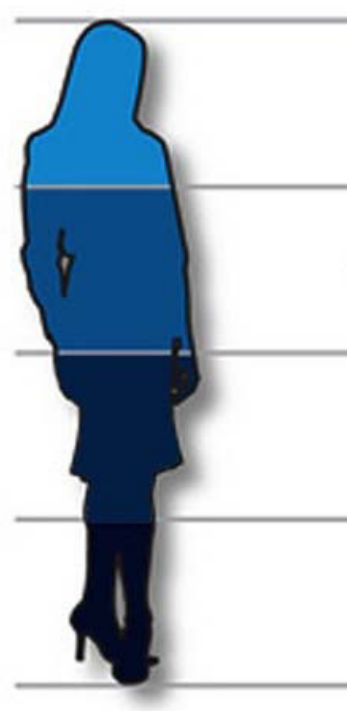

Cognitive aspect:

use fixation, technical skill, spatial reasoning, adaptability, sensitivity to

stereotype, reading manuals, literacy, memory, and prerequisite content knowledge

\section{Personality:}

patience, locus of control, optimism, perfectionism, changeability, uncertainty avoidance, self-efficacy, and exposure to marketing,

\section{Demographics:}

age, gender, culture, income, and grown-up place

\section{Use behavior:}

frequency of use, avoidance of using complex products, buy decision,

complaining behavior, familiarity with electronics, and trust of shop assistants

Figure 2: dimensions of user characteristics

In total three surveys and one experiment were conducted. The first survey was a questionnaire survey to explore what usability problems users experienced in the Netherlands and South Korea. This study resulted in the categorization of soft usability problems. The second survey investigated how user characteristics are related to the occurrence of specific soft usability problems. Finally, an experiment was conducted to find out how user characteristics are correlated to specific soft usability problems depending on type of product in the USA, South Korea and the Netherlands. Based on the findings from the studies, user profiles will be developed which provide insight into the interaction between user characteristics, product type, and soft usability problems. Based on this an interactive tool will be developed: UPS (User characteristics, Product type and Soft Usability problems). Companies can use UPS to gain insights into probable usability problems of a product they are developing and the characteristics of those who would have problems using the product.

\subsection{Improving usability decisions in design practice}

Usability principles and techniques have been around for 30 years now and despite this, many users still experience usability problems with electronic consumer products [20, 21: p.825]. These problems are ultimately caused by the decisions made in the development process [15]. In general decisionmaking literature, uncertainty is mentioned as an important factor influencing the quality of decisions.
This factor is also acknowledged in design literature, but no approaches are described to cope with uncertainty (= the lack of information) in the design context.

This project aims to improve the usability-related decision-making in design practice. It explores the critical factors that influence the quality of usabilityrelated decision-making.

The initial literature study was followed by an explorative case study at a design agency to identify the influences on usability decision-making. These investigations showed that there are three important issues related to decision-making: 1) Uncertainty, lack of usability information; 2) Awareness, do the actors realise that there is a lack of usability-related information; and 3) Time, is there time to collect the lacking information (with user research or usability evaluation methods)?

The second study investigated whether the currently available user research or usability evaluation methods are adequate when addressing the factors uncertainty and unawareness. The results of this study showed that methods applied for user research and usability evaluation almost entirely address the factor 'uncertainty'.

To investigate whether usability problems result from 'unawareness', a third case study was conducted at a large-scale multinational product development company, which has skilled and knowledgeable designers and a well-defined development process for developing usable products. The analysis of the 14 retrospective interviews shows that usability problems result from 'unawareness' in 
lems result from 'unawareness' in the conceptual phase of the design project. Through analysis of the 155 most important documents a better understanding of unawareness during decision-making was gained.

Combining the results of the different studies suggests that to prevent usability problems resulting from 'unawareness', a different approach than applying the existing usability techniques is necessary. Based on the examples found in the third study and existing literature, an approach to prevent unawareness was discussed.

\subsection{Product Impact}

The dominant approach in design theory is that for designing good, useful, user-friendly products, it is important to understand user needs and characteristics. However, technologies shape and transform user needs and behavioural routines. To improve usability, the focus must not be exclusively on user needs and characteristics, but also on the complementary aspect of how technology changes people. The reconfiguration of behavioural routines and preferences by technology is an important topic in the philosophy of technology. To date, little of this knowledge has been transferred to design practice. The Product Impact project therefore investigates how knowledge of the behaviour changing effects of technology can be integrated in product design. Can Product Impact knowledge help to anticipate and avoid use problems? Is it possible to design products that deliberately guide and change user behaviour? An explicit part of the project is to consider the ethical dimensions of this view on technology and the profession of design.

The Product Impact project aims to improve understanding of how users change in the process of interaction with products, and to integrate this knowledge in design practice, by means of a Product Impact Tool. In this way, the project contributes to improved understanding of human-technology interaction and the practice of design for usability.

The Product Impact research has resulted in papers and publications on relevant theories about product impact and usability, on changes in humans and society in the history of design, and about analysing the ethical aspects of behaviour changing technology. Based on this research, a Product Impact Tool is being developed, consisting of a model that frames different types of product impact, and a format for organising a Product Impact Session.
In a Product Impact Session a concept, prototype or existing product is analysed with the purpose of discovering the changing effects of technology on users. To achieve this, one has to deliberately think the other way around: not from user needs to a technical solution, but from a product (or concept, prototype) to its possible effects on the user. The Product Impact Tool structures this analysis. In this way userchanging effects are revealed and ideas for redesigns will be generated.

The Product Impact project combines knowledge from philosophy and behavioural sciences with engineering and design in an innovative way. In engineering, technology is mostly considered instrumental means to fulfil human needs. In philosophy and social sciences, technology is often shown to change people in ways they had not foreseen themselves. Therefore, technology changes humans, and should not simply be considered as a means to fulfil needs that were always there. The recombination of both perspectives is innovative and promising for enhancing human-technology interaction and usability.

\section{Conclusion}

The Design for Usability research project, with its aim of improving how usability is dealt with in 'real life' product development, required a practiceoriented research approach. In a discussion of research in the medial sciences Malterud [50] argues that in addition to controlled experiments, with their focus on questions and phenomena that can be controlled, measured and counted, the knowledge of experienced practitioners should be studied, because that could offer a broader understanding of a phenomenon. The DfU project adopted this 'practitioner-centered' research approach. Firstly, parallel to initial exploration of the topic by reviewing literature, interviews were conducted with usability practitioners and experts. Secondly, a major part of data collection was conducted through case studies [51] in product development practice. Finally, the DfU project involved regular member checks [52]: throughout the studies informants verified interpretations and conclusions, and each of the sub-projects included at least one feedback workshop in which the results and conclusions were discussed with practitioners.

Overall, the Design for Usability project resulted in 1) a reference methodology for organizing product development processes and organizations if the goal is to make usable products, 2) new methods for user- 
centred design and 3) new insights in issues obstructing the creation of usable products in product development practice

Because the goal was to improve product development practice, in addition to the scientific publications, an essential aim was to effectively communicate project results to practitioners through: 1) Three Design for Usability symposia on World Usability Day (2009/2010/2011), 2) A Design for Usability 'Methods \& Tools' book, supported by content on the project website, 3) Workshops with product development practitioners.

The feedback from industry so far has been extremely positive. The DfU project demonstrates that a practice-oriented research approach can contribute to the creation of design methodologies that can be directly applied by practitioners.

\section{Acknowledgements}

The authors gratefully acknowledge the support of the Innovation-Oriented Research Programme 'Integral Product Creation and Realization (IOP IPCR)' of the Netherlands Ministry of Economic Affairs, Agriculture and Innovation.

\section{References}

[1] B. Shackel, "The concept of usability," in Visual Display Terminals, J. Bennet., Ed., ed Englewood Cliffs, New Jersey: Prentice-Hall, Inc., 1984, pp. 45-81.

[2] M. Hertzum, "Images of Usability," International Journal of Human-Computer Interaction, vol. 26, pp. 567-600, 2010.

[3] ISO, "ISO 9241-11 Ergonomic requirements for office work with visual display terminals (VDTs) - Part 11: Guidance on usability," International Organization for Standardization, Geneva, Switzerland ISO 9241-11:1998(E), 1998.

[4] P. W. Jordan, An Introduction To Usability: Taylor and Francis, 1998.

[5] T. Jokela, N. Licari, J. Matero, and M. Karukka, "The standard of user-centred design and the standard definition of usability: analyzing ISO 13407 against ISO 9241-11," in Proceedings of the Latin American Conference on HumanComputer Interaction, Rio de Janeiro, Brazil, 2003, pp. 53-60.

[6] D. J. Mayhew, "Business: Strategic development of the usability engineering function," Interactions, vol. 6, pp. 27-34, 1999.

[7] ISO, "ISO 20282-1:2006 Ease of operation of everyday products -- Part 1: Design requirements for context of use and user characteristics " International Organization for Standardization 2006

[8] W. H. Cushman and D. J. Rosenberg, Human Factors in Product Design. Amsterdam: Elsevier Science Publishers, 1991.

[9] G. M. Donahue, " Usability and the bottom line," Software, IEEE , vol. Vol.18, pp. 31-37, 2001.
[10]E. Frøkjaer, M. Hertzum, and K. Hornbaek, "Measuring usability: are effectiveness, efficiency, and satisfaction really correlated?" presented at the Proceedings of the SIGCHI conference on Human factors in computing systems, The Hague, The Netherlands, 2000.

[11]G. Lindgaard and C. Dudek, "What is this evasive beast we call user satisfaction?," Interacting with Computers, vol. 15, pp. 429-452, 2003/6 2003.

[12]T. Rooden, "Design models for anticipating future usage," $\mathrm{PhD}$ thesis, Faculty of Industrial Design Engineering, Applied Ergonomics and Design, Delft University of Technology, Delft, 2001.

[13]P. W. Jordan, "Human factors for pleasure in product use," Applied Ergonomics, vol. 29, pp. 25-33, 1998/2 1998.

[14]E. Demir, P. M. A. Desmet, and P. Hekkert, "Appraisal Patterns of Emotions in Human-Product Interaction," International Journal of Design, vol. 3, pp. 41-51, 2009.

[15]E. Den Ouden, "Development of a design analysis model for consumer complaints : revealing a new class of quality failures " $\mathrm{PhD} \mathrm{PhD}$ thesis, Department of Technology Management, Section Product and Process Quality, Eindhoven Technical University, Eindhoven, 2006.

[16]F. F. Reichheld, "The one number you need to grow," Harvard Business Review, vol. 81, pp. 46-55, Dec 2003.

[17]T. Otker, M. Schellekens, H. v. Leeuwen, and R. Heutink, "True Loyalty - The predictive value of customer satisfaction indicators," in ESOMAR 2005 congress; proceedings, part 1: customer focus, Cannes, France, 2005.

[18]C. W. Park, L. Feick, and D. L. Mothersbaugh, "Consumer knowledge assessment: How product experience and knowledge of brands, attributes, and features affects what we think we know," Advances in Consumer Research, vol. 19, pp. 193-198, 1992.

[19]A. C. Brombacher, "Reliability in strongly innovative products; a threat or a challenge?," Reliability Engineering \& System Safety, vol. 88, pp. 125-125, 2005.

[20]E. Den Ouden, L. Yuan, P. J. M. Sonnemans, and A. C. Brombacher, "Quality and Reliability Problems from a Consumer's Perspective: an Increasing Problem Overlooked by Businesses?," Quality and Reliability Engineering International, vol. 22, pp. 821-838, 2006.

[21]T. Steger, B. Sprague, and D. Douthit, "Big Trouble with No Trouble Found: How Consumer Electronics Firms Confront the High Cost of Customer Returns," Accenture2007.

[22]F. W. B. Hoolhorst and v. d. M. C. Voort, "A concept for a usability focused design method," presented at the IASDR 2009, Seoul, 2009.

[23]J. I. van Kuijk, "Managing Product Usability; How companies deal with usability in the development of electronic consumer products," PhD PhD, Faculty of Industrial Design Engineering, Delft University of Technology, Delft, 2010.

[24]H. Christiaans, "Creativity in design," PhD, Industrial design engineering, TU Delft, Delft, 1992.

[25]K. Dorst, "Design research: a revolution-waiting-to-happen," Design studies, vol. 29, pp. 4-11, 2008.

[26]F. W. B. Hoolhorst, "Title," unpublished|.

[27]J. I. Van Kuijk, "Managing product usability: How companies deal with usability in the development of electronic consumer products," PhD, Industrial design engineering, TU Delft, Delft, 2010.

[28] N. Cross, Designerly ways of knowing. Basel, Boston, Berlin: Birkhäuser, 2006.

[29]N. Cross, H. Christiaans, and K. Dorst, Analysing design activity. Chichester: John Wiley and Sons Ltd., 1996.

[30]I. C. Boivie, J. Gulliksen, and B. Goransson, "The lonesome cowboy: A study of the usability designer role in systems 
development," Interacting with computers, vol. 18, pp. 601634, 2006.

[31] J. I. Gulliksen, I. C. Boivie, and B. Göransson, "Usability professionals--current practices and future development," Interacting with computers, vol. 18, pp. 568-600, 2006.

[32] M. Kleinsmann, "Understanding collaborative design," $\mathrm{PhD}$, Industrial design engineering, TU Delft, Delft, 2006.

[33] G. Pahl and W. Beitz, Engineering design. London: Design Counsil, 1996.

[34]"Methodik zum entwickeln und konstruieren technischer Systeme und Produkte," V. D. Ingenieure, Ed., ed. Düsseldorf: VDI, 1986.

[35] J. Daalhuizen, P. Badke-Schaub, and J. Fokker, "Community Based Design Support," in Proceedings TMCE 2008 conference, Izmir, 2008.

[36]N. Bevan, "UsabilityNet Methods for User Centred Design.," presented at the Human-Compuer Interaction: Theory and Practice (Part 1), Volume 1 of the Proceedings of $\mathrm{HCI}$ International, Heraklion, Crete, Greece, , 2003.

[37]N. Stanton and M. Young, "Is utility in the mind of the beholder? A study of ergonomics methods," Applied Ergonomics, vol. 29, pp. 41-54, 1998/2 1998.

[38] J. Nielsen and R. L. Mack, Usability inspection methods. New York: Wiley, 1994.

[39] T. Jokela, "When good things happen to bad products: where are the benefits of usability in the consumer appliance market?," Interactions, vol. 11, pp. 28-35, 2004.

[40]D. Pogue, "Heavily hyped cellphone won't make you a chocoholic," in New York Times, ed. New York, 2006.

[41]B. Shackel, "Usability - context, framework, definition, design and evaluation," in Human factors for informatics usability, B. Shackel and S. J. Richardson, Eds., ed Cambridge: Cambridge University Press, 1991, pp. 21-37.

[42]K. D. Eason, "Towards the experimental study of usability," Behavioral and Information Technology, vol. 3, pp. 133-143, 1984.
[43]S. a. Y. Lauesen, H., "Six Styles for Usability Requirements," presented at the REFSQ '98, Namur, France, 1998.

[44] S. H. Han, M. H. Yun, J. Kwahk, and S. W. Hong, "Usability of consumer electronic products," International Journal of Industrial Ergonomics, vol. 28, pp. 143-151, 2001/0 2001.

[45]S. Babbar, R. Behara, and E. White, "Mapping product usability," International Journal of Operations \& Production Management, vol. 22, pp. 1071 -- 1089, 2002.

[46] A. Koca, M. Funk, E. Karapanos, A. Rozinat, W. M. P. v. d. Aalst, H. Corporaal, J. B. O. S. Martens, P. H. A. v. d. Putten, A. J. M. M. Weijters, and A. C. Brombacher, "Soft Reliability: An Interdisciplinary Approach with a User-System Focus," Quality and Reliability Engineering International, vol. 25, pp. 3-20, 2008.

[47]K. R. d. Leur, J. W. Drukker, H. H. C. M. Christiaans, and T. R. A. d. Rijk, "Cultural differences in product design: a study of differences between the South Korean and the Dutch kitchen environment," Journal of Design Research, vol. 5, pp. 16-33, 2006.

[48]C. J. Kim, H. H. C. M. Christiaans, and J. C. Diehl, "Exploring the influence of culture in consumer electronic products," presented at the 16th World Congress on Ergonomics, Maastricht, The Netherlands, 2006.

[49] J. Rodríguez, J. C. Diehl, and H. H. C. M. Christiaans, "Gaining insight into unfamiliar contexts: a design toolbox as input for using role-play techniques.," Interacting with Computers, vol. 18, pp. 956-976, 2006.

[50]K. Malterud, "The art and science of clinical knowledge: evidence beyond measures and numbers," The Lancet, vol. 358, pp. 397-400, 2001.

[51]R. K. Yin, Case study research: design and methods, 4th edition ed. Thousand Oaks, California, USA: SAGE publications, Inc., 2009.

[52]A. K. Shenton, "Strategies for ensuring trustworthiness in qualitative research projects," Education for Information, vol. 22, pp. 63-75, 2004. 